\title{
Integration of MOOCs in Advanced Mining Training Programmes
}

\author{
Irina Saveleva ${ }^{1,{ }^{*},}$ Oksana Greenwald ${ }^{1}$, Svetlana Kolomiets $^{1}$, and Elena Medvedeva ${ }^{1}$ \\ ${ }^{1}$ Kemerovo State University, Institute of Philology, Foreign Languages and Media Communication, \\ Department of Foreign Languages, 650000 Kemerovo, 6 Krasnaya st., Russian Federation
}

\begin{abstract}
The paper covers the concept of innovative approaches in education based on incorporating MOOCs options into traditional classroom. It takes a look at the ways higher education instructors working with the mining engineers enrolled in advanced training programmes can brighten, upgrade and facilitate the learning process. The shift of higher education from in-class to online format has changed the learning environment and the methods of teaching including professional retraining courses. In addition, the need of mining companies for managers of a new kind obligates high school retraining centres rapidly move towards the $21^{\text {st }}$ century skill framework. One of widely recognized innovations in the sphere of elearning is MOOCs (Massive Open Online Courses) that can be used as an effective teaching tool for organizing professional training of managing staff of mining companies within the walls of a university. The authors share their instructional experience and show the benefits of introducing MOOCs options at the courses designed for retraining mining engineers and senior managers of coal enterprises. Though in recent researches the pedagogical value of MOOCs is highly questioned and even negated this invention of the $21^{\text {st }}$ century can become an essential and truly helpful instrument in the hands of educators.
\end{abstract}

\section{Introduction}

The demands of the modern information age compel higher education graduates and those people who already have working place to be equipped with the 21 st century skills. This set of skills will allow professionals to achieve great results in their career and to make a significant contribution to society or industry. According to the Partnership for 21 st Century Skills' list the most valuable qualities to a new high school graduate and to employers are flexibility and adaptability, collaboration and teamwork, creativity, imagination, critical thinking, problem solving. They all interact with each other, e.g. creativity and imagination go hand-in-hand with critical thinking and problem solving.

\section{Materials and Methods}

*Corresponding author: saviren1973@mail.ru 
Giving an extensive survey on $21^{\text {st }}$ century skills Thrilling and Fadel note that flexibility and adaptability can be learned by working on progressively more complex projects that make students change decisions and ways when things aren't working well, adapt to new developments in the project, and incorporate new team members on both current and new projects". To develop critical thinking and problem solving skills it is necessary to make judgments and decisions, analyze and evaluate, synthesize and make connections between information and arguments, etc. [1].

"The increase in the number of service-sector jobs, which include high-growth, highwage and high skilled occupations in new and emerging occupations, requires students to have different skills and a greater familiarity with technology than ever before [2]". Seniors of coal industry also want their managers of different level working for mining companies to gain the skills necessary to participate in a global economy. As CEOs of coal industry all over the world claim, the prior strategies of mining enterprises are as follows: moving collaborative research beyond regional boundaries to global market, to increase competency creating a mining research and innovation projects effectively linking research capability to industry needs $[3,4]$.

Thus, retraining courses organized for this group of adult learners should both meet the requirements of their current needs and supply the effective teaching schedule developing the set of $21^{\text {st }}$ century skills. Recent researches in the sphere of teaching methods show that application of one or two approaches does not result in high learning outcomes and, therefore, does not shape the set of skills required. Combination of face-to-face and online teaching formats especially used for retraining programmes is the call of the time [4-7]. Incorporating distance learning elements into traditional classes lead to such innovative techniques as "hybrid teaching" or "blended teaching" [8]. The idea of integrating MOOCs into university training programmes is one of the possible solutions. In order for teachers to deliver quality in both face-to-face and online learning environments, it is pivotal that they experience and understand MOOC options [5]. Indeed, education is now at a turning point and this is going to occur rapidly at a global scale and massive courses are just the beginning [9].

\section{Results and Discussion}

Massive Open Online Course (MOOC) is a technology that provides educational courses via online to a considerable number of people for free of charge or at an affordable cost. It is open to anyone who is interested in receiving knowledge and education. MOOCs are commonly offered via a web-based platform [10]. There are two types of MOOCs cMOOCs and xMOOCs. Commonly, xMOOC consists of short video lectures, quizzes, self-graded / peer-graded assignments and forum to facilitate the communications and collaborations [11]. Typically, this kind of a course expands 4-8 weeks and could be taken on scheduled dates or self-phased. The other type, cMOOC, uses social media to connect people with the information of Open Educational Resources and stimulates the participants' discussion and collaboration.

The term MOOC originated in Canada in 2008 being coined to describe the online course Connectivism and Connected Knowledge designed by George Siemens and Stephen Downes. Then, in 2012, MOOC evolution took place when the University of Stanford organized the Artificial Intelligence course, attracting over 100.000 interested learners. MOOCs were new and they shook the educational establishment [2].

Larger corporations such as Pearson and Google are also planning to move into the sector of higher education as global players and are likely to adopt a MOOC-based approach as a part of their plans. Recently a new company, Futurelearn, has been launched by the Open 
University in the UK, to bring together a range of free, open, online courses from leading UK universities for learners around the world [12].

A report for the Becta agency [5] on technology-assisted learning identified 17 essential learning practices that might be delivered or supported by the technology. These include: expository, reflective, networked, tutored, case-based, problem-based, inquiry-driven, game-based, and constructive. MOOCs is to provide teaching by video, with opportunities for learners to pause the presentation and reflect or respond vocally, and for educators to embed formative quizzes into the video. The problem is that, while direct instruction by lecturing works at massive scale to engage learners and introduce big topics, this is a less effective approach to teaching than more active and collaborative pedagogies [13].

Since then a lot of MOOC research and experimenting has been done resulting in a better understanding of how MOOC can help teachers and learners in this new eLearning era. MOOCs are seen to become a framework of an innovative, comprehensive strategy for evolving education to meet the needs of 21 st century society [1].

Though in the beginning of MOOCs dissemination at the learning market this platform was exploited apart from traditional education patterns, rather independently, some educators considered massive courses from a different perspective and introduced a new approach to teaching university students borrowing MOOCs options. This was due to an attempt to build a new model of a student centered classroom instead of a teacher centered classroom as well as to change the learning resources by incorporating e-resources into education of any level. Thus, there have appeared some researches where combined teaching principles were claimed, described and justified $[5,7,8,11]$.

Yet pedagogical value and effectiveness of MOOCs was called into question [7, 10, 12 , 14]. For instance, Armellini and Rodriguez think that MOOCs as open educational resources are often re-structured as courses with teachers' participation. This traditionally results in mere transmission of content. The researchers conclude that this approach is hardly an innovative pedagogical practice [14]. As for the concept of MOOCs it is often doubted that they really provide education to anyone who has a desire to develop intellectual abilities as they cannot access any course without payment. Some MOOCs are open and massive, but they are not many [12].

According to Inge de Waard, online education does not vary much from sound, face-toface learning in its pedagogical essence. MOOCs based on the importance of dialogue being present at the core of a MOOC. Never the less, dialogue between participants immediately moves the focus from content-to-learner toward learner-to-learner dynamics. MOOCs, and particularly the connectivist MOOCs lend themselves for problem-based learning, as they rely in part on enquiry based peer interactions and these learning models benefit from more interaction and access to information [5]. As Maria Israel states in her study "incorporating MOOCs in traditional classroom settings was almost equal or slightly better than face-to-face teaching environments [8]".

Certain scholars suggested to infuse the EFL class with some of these ideas in order to optimize learning outcomes by introducing the innovative method of flipped classroom (a type of a lesson where students discuss and analyze content they familiarized with before coming to the lesson, mostly practice and master their skills) [15-17].

Nowadays the two types of MOOCs are mostly presented by Coursera and FutureLearn as the most widespread massive education platforms. The main difference between them being the underlying pedagogy, they both are useful tools to apply for training qualified specialists.

The courses offered by xMOOCs (Coursera) are using the instructive (or transformative) approach. As it was mentioned above they usually contain fragmented video lectures, additional material for reading, multiple-choice quizzes, self-graded/ peer graded assignments and forums for discussion. However, the really working parts of it are the following: 
firstly, a video (as it usually provides interesting and significant information); secondly, multiple choice quizzes (as they are not easily answered and require full understanding, analyzing and rethinking of the given material), thirdly, some assignment (as it gives some practical application of the knowledge and skills obtained).

As for the forum is concerned, it does not work to the full and students prefer to communicate and discuss problems in personal contact, face-to-face. Lacking in organizing real massive communication, this kind of MOOCs is still a very useful tool of training a professional in the 21 st century as it provides good opportunities for developing necessary skills.

First of all, blending traditional face-to-face teaching with a suitable course (or a part of it) in MOOCs allows the teacher to show the different approaches to the same problem especially in case of the course developed in another country or university because each one has its own peculiarities, national or institutional. The students are asked to enroll for the course and pass it (or at least part of it) before the usual class, then the teacher can organize discussion or some problem-solving group task demanding knowledge and skills obtained at the course to cope with.

It is also important that the students can schedule their doing the tasks of the course according to their own pace as the participants of retraining courses are busy working people and are not able to spend much of their time at the university or any other educational centre. The educational institutions in their turn are also interested in offering the most effective training with as small number of classroom hours as possible offering different ways of organizing self-study.

The courses of the second type (cMOOCs) which can be found at FutureLearn are based on connectivist or constructivist approaches. The first make use of social media connecting people and information thus enabling people to learn more. The second (social constructivist) apply to the theory of learning effectively in conversations with yourself and others. In this case, the content of the course, its questions and given problems serve as a starting point for the participants to build their learning process. The latter can take part in the discussions, add their own resources and produce their contextualized content. Hence, this type of MOOCs is more suitable for developing such skills as collaboration, creativity, teamwork and problem solving. It requires a high level of participant's motivation, though. Taking into consideration that some of our target audience are highly motivated professionals this kind of courses appears to be extremely useful and effective for them as it gives the opportunity to put into practice their knowledge and to solve real problems while studying.

All these views support our idea of integrating MOOCs options into advanced mining training programmes. This was done during President courses aimed to master language skills of Kuzbass mining companies managerial staff. First of all, some MOOCs were selected and partially included into the syllabus. It should be noted that online lessons created by leading British, American and Australian universities and disposed on Coursera, FutureLearn, Edx and Open2Study Platforms provide short specialized open courses that can boast their authenticity in regards to the language presented and the sound ideas outspoken. They offer the courses that provide information and practice in the sphere of management as well as mining and include diverse theme modules and multi-purpose content.

For example, the course "Developing the Opportunity for Corporate Entrepreneurs" disposed on Coursera is designed for managers of different level from junior to senior working for companies interested in learning how to innovate and apply entrepreneurship principles in the corporate setting. Learners will develop knowledge on how to navigate the barriers to creating, developing, and sustain innovative new businesses within large companies. These new businesses rarely fit neatly within well-established systems, processes, and cultures. Learners will develop the skills, and learn the tools and best practices, for identifying and developing the entrepreneurial opportunities, building business models, creating 
strategies for leading innovation, and financing innovation [18]. The following modules and discussion-provoking topics have been practiced:

- Setting up a formal structure for corporate entrepreneurship.

- Key enablers of corporate entrepreneurship.

- What is strategic decision-making?

- Why study strategic decision-making?

- What is your decision-making style?

- Designing a career path for corporate entrepreneurs

- Do you have a high need for achievement?

- How does individualism influence your decision-making?

- Do you believe that you have control of your own destiny?

- Are you able to effectively focus your time and resources?

- Is the industry advertising intensive?

- Are you trying to enter a concentrated market?

- What is the average size of a company in the industry?

More specific programmes provided by Edx and Open2Study were optionally incorporated into the syllabus of the programme designed for professional training of mining company managers. Edx MOOC runs the course called "The Business of Mining". The content presented includes four modules:

1. Exploration. The students were able to analyse geophysical surveys and geochemical data.

2. Mine Planning. The Round Table discussions were devoted to the following problems:

- What infrastructure will you build to run your mine?

- Will you use a local workforce, or a fly-in/fly-out model?

- What are you planning to do with your mine waste?

- Can you pay for all of this and still make a profit?

3. Operation. Trainees mostly touched practical points, e.g. "Process your ore and recover as much gold as you can. Sounds pretty simple, until the gold price takes a tumble and suddenly your mine plan needs adjusting".

4. Closure and Post-closure. This module included lectures, pedagogical tasks and tests concerned with scarce supplies: "Nothing lasts forever, particularly in mining. Eventually you're going to run out of gold, or the market will change and your profit margin will disappear. How will you ensure you leave a safe, rehabilitated site?" [19].

If the programme syllabus counted fewer hours of face-to-face in-class study the method of flipped classroom was effectively applied. Typically, flipped teaching format presupposes substantial hours for self-study and gives students the opportunity to be engaged into larger number of practical tasks and project making assignments when working in the classroom.

"Mining Engineering" course created by the University of Newcastle, Australia and logged on Open2Study educational platform allows those who are mastering their professional skills to learn: the steps in the mining process from mineral exploration to closure; fundamentals of Rock Mechanics (stress-strain, rock strength, effect of discontinuities, rock testing, stress in the ground and instabilities); fundamentals of surface and underground mining including terminology, types of operations, economics and safety. Preparing for the class students can watch video content on the mining process, mining geomechanics, surface mining, underground mining. Yet, in the class they are to interpret information they familiarized with, solve different kinds of problems they face at work in both conventional and innovative ways, draw conclusions in groups and individually. 
Combined teaching approaches applied for retraining coal industry managers that exploit MOOCs platforms, content and techniques, format and assessment patterns can be effectively used for developing $21^{\text {st }}$ century skills listed and described above. Using fragments of MOOCs, which are designed exactly for mining company workers, the instructors can enable trainees to acquire professional knowledge as well as to apply creative and critical thinking. While the adult learners can be involved into the process of watching and listening the teacher is able to mediate the learning situations and participate launching the discussions that require the ability of trainees to work in a team and to interact with each other in order to work out a solution (problem solving activities and tasks). Project work based on MOOC content can also help professionals practice and master their teambuilding and collaboration skills, they get more complex vision and understanding of global technologies and economies.

\section{Conclusion}

MOOCs as an innovative education framework have been and remain a controversial issue. One of the reasons is that they are still being exposed to the process of evolution.

However, the era of information technology, expansion of learning and extensive use of information sets its requirements for both teachers and learners.

Education of the $21^{\text {st }}$ century tends to apply teaching formats and approaches that integrate learning strategies, digital competences and career abilities and MOOCs implementation into the learning process can serve as such. Using complete MOOCs or integrating parts of them according to the personal needs and abilities of the learners into the process of study allows to develop skills necessary for a $21^{\text {st }}$ century professional.

To sum it all up, MOOCs act as a great stimulus for intellectual activities of professional mining engineers and encourage their desire for further self-education and implementation of obtained skills at the working place. It is crucial that their digital and technological skills are enhanced.

\section{References}

1. B. Trilling, Ch. Fadel. $21^{\text {st }}$ Century Skills. Learning for life in our times (Jossey-Bass, USA, 2009)

2. Hanover Research. A Crosswalk of 21st Century Skills. (Washington DC, USA, 2011)

3. J. L. Kohler, Int. J. Min. Sci. Tech. 25:3, 325- 332 (2015)

4. G. Johnson. Strategic Change and the Management Process. (Oxford: Blackwell, 1987)

5. I. de Waard, Revista Mexicana de Bachillerato a Distancia, 7:13, (2015)

6. R.Williams, R. Karousou, J. Mackness, Int. Rev. Res. Open Dist. Learn. 12:3, 39-59 (2011)

7. R. Ferguson, D. Clow, R. Beale, A. Cooper, N. Morris, S. Bayne, A. Woodgate, Design for Teaching and Learning in a Networked World, Lecture Notes in Computer Science (Springer International Publishing Switzerland, 2015)

8. M. Israel, Int. Rev. Res. Open Dist. Learn. 16:5 (2015)

9. O. Shapira-Lishchinsky, Teaching and Teacher Education, 27 (2011)

10. S. Bayne, J. Ross, The pedagogy of the Massive Open Online Course: the UK view (Higher Education Academy, the University of Edinburgh, 2014)

11. J. Daniel, J. Interact. Med. Ed. 3 (2012) 
12. I.de Waard, S. Abajian, M. Gallagher, R. Hogue, N. Keskin, A. Koutropoulos, \& O. Rodriguez, Int. Rev. Res. Open Dist. Learn. 12:7, 94-115 (2011)

13. M. Prince, J.1 Engin. Educ., 93:3 223-231 (2004)

14. A. Armellini, B. Rodriguez, J. Interact. On. Learn. 14:1, 17-28 (2016)

15. Y. Parra Sr., Gist Educ. Learn. Res. J., 7, 190-208 (2013)

16. M. Bali, Int. Rev. Res. Open Dist. Learn. 10:1, $44-57$ (2014)

17. Ya. Parra, GIST Educ. Learn. Res. J. 7, 190- 208 (2013)

18. MOOC Resource, Developing the Opportunity for Corporate Entrepreneurs URL: https://www.coursera.org/learn/corporate-entrepreneurs-opportunity 08.09.2017)

19. MOOC Resource, The Business of Mining URL: https://www.edx.org/course/businessmining-curtinx-tbomx-0\# (Accessed: 08.09.2017) 
